improve peripheral perfusion to an extremity and improve the reliability of a poorly functioning pulse oximeter. Two caveats exist. Firstly, the reason for poor perfusion should also be sought and treated (e.g., hypovolemia, sepsis). Secondly, great care must be taken to avoid thermal injury by appropriate diffusion of air flow and regular inspection of the limb.

Robin Cox FRCPC

Calgary, Alberta

\section{Laryngeal mask airway for preserva- tion of the external branch of the supe- rior laryngeal nerve during thyroid surgery}

To the Editor:

We read with interest the article by Hillerman et al. ${ }^{1}$ concerning laryngeal nerve identification during thyroid surgery using the laryngeal mask airway (LMA). Although postoperative voice changes are usually attributed to recurrent laryngeal nerve injury, the external branch of the superior laryngeal nerve (EBSLN) is also at risk since it runs close to the superior thyroid artery, which is ligated during surgery. ${ }^{2}$ Injury to the EBSLN occurs in $4-10 \%^{3,4}$ of patients and results in huskiness and voice fatigue since it is the only motor supply for the cricothyroid muscles, which tense the vocal cords. Identification of the EBSLN and individual ligation of the superior thyroid vessels

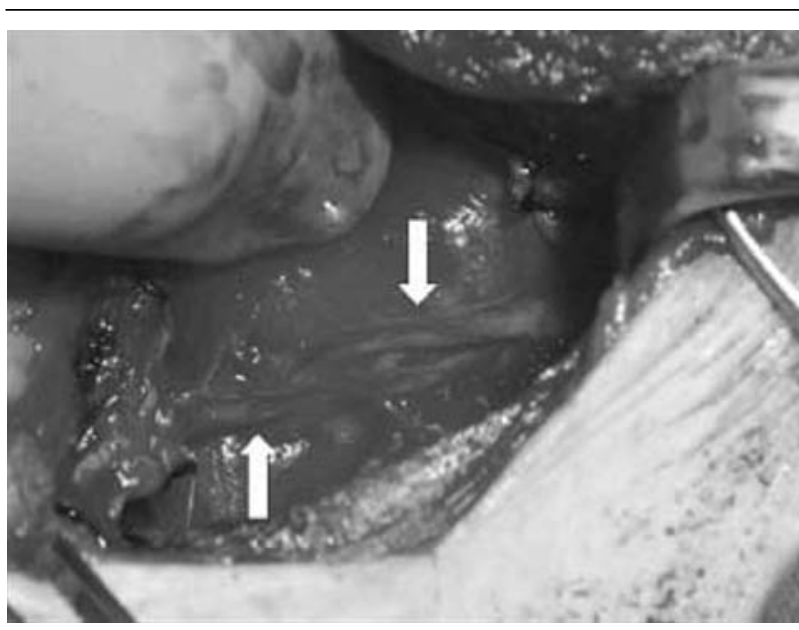

FIGURE Thyroid surgery with the laryngeal mask airway. View of left side of the neck during dissection. By splinting open the pharynx, the cuff facilitates identification and preservation of the external laryngeal nerve and its branches (arrows). are imperative to avoid injury. A particular problem during dissection is that the pharyngeal wall is soft and collapsible making exposure of the EBSLN difficult. A technique we discovered which overcomes this problem is to use the LMA to control the tension and position of the pharyngeal wall. The technique involves insertion of the LMA behind the tracheal tube and inflation of the cuff until the surgical conditions are optimal. The technique can also be used when the LMA is the ventilatory device, but the range of cuff volumes is more restricted since the seal with the pharynx must remain intact. We have used this technique on 17 patients and have had no problems with location of the EBSLN.

Joseph Brimacombe MB CHB FRCA MD

John Knott MB BS FRCS FRACS

Cairns, Australia

Christian Keller MD

Innsbruck, Austria

\section{References}

1 Hillermann CL, Tarpey J, Phillips DE. Laryngeal nerve identification during thyroid surgery - feasibility of a novel approach. Can J Anesth 2003; 50: 189-92.

2 Delbridge L, Samra J. Editorial: the 'neglected' nerve in thyroid surgery--the case for routine identification of the external laryngeal nerve (Letter). ANZ J Surg 2002; 72: 239 .

3 McIvor NP, Flint DJ, Gillibrand J, Morton RP. Thyroid surgery and voice-related outcomes. Aust N Z J Surg 2000; 70: 179-83.

4 Rosato L, Mondini G, Ginardi A, Clerico G, Pozzo M, Raviola P. Incidence of complications of thyroid surgery. Minerva Chir 2000; 55: 693-702.

\section{Prophylactic iv metaraminol during spinal anesthesia for elective Cesarean delivery}

To the Editor:

The use of potent vasopressors to combat maternal hypotension following spinal anesthesia for Cesarean delivery is increasingly common despite initial concerns of fetal compromise. ${ }^{1}$ Metaraminol is a mixed alphaand beta-adrenergic agonist with a predominant alpha effect at a clinical dose. A recent study showed that it is associated with less neonatal acidosis and more closely controlled arterial pressure compared with ephedrine. ${ }^{2}$ This double-blinded study evaluated prophylactic metaraminol on fetal acid-base status. 